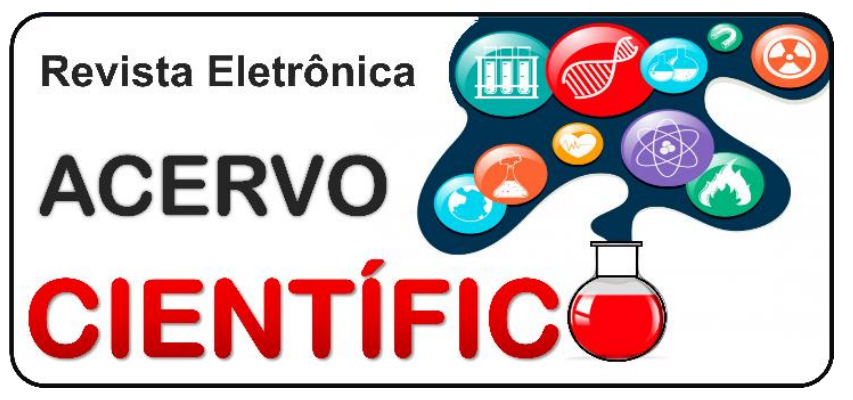

ARTIGO ORIGINAL

Recebido em: 12/2019

Aceito em: $12 / 2019$

Publicado em: 5/2020

\title{
Ingestão dietética de alimentos ricos em FODMAPs em portadores da síndrome do intestino irritável
}

\author{
Dietary intake of rich foods in FODMAPS in carriers of irritable intestinal syndrome \\ Ingestión dietética de alimentos ricos en FODMAPS en portadores del síndrome del \\ intestino irritable
}

Karyna Batista de França Teles ${ }^{1}$, Shérlyda Memória de Sousa ${ }^{1}$, Liejy Agnes dos Santos Raposo Landim ${ }^{2 *}$.

Resumo: Elucidar a influência da dieta rica em FODMAPs nos sintomas de pacientes com Síndrome do Intestino Irritável. Trata-se de um estudo de caso múltiplos, realizado com pacientes que possuíam síndrome do intestino irritável, conduzido em seis indivíduos do sexo feminino. Foram analisados parâmetros de avaliação clínica e dietética, incluindo recordatório 24 horas e questionário de frequência alimentar adjunto de dados antropométricos para resultar no estado nutricional das participantes. Além disso, foi questionado os principais sintomas e causas da exacerbação da sintomatologia. Os dados foram quantificados em gráficos e tabelas do Microsoft Excel 2016, para análise descritiva. Em relação ao estado nutricional, as pacientes apresentaram resultados diversos, não havendo prevalência. $\mathrm{Na}$ análise alimentar foi possível avaliar que a maioria das pacientes não estava com a ingesta calórica, glicídica, protéica e lipídica adequada, de acordo com os parâmetros comparados. Observou-se também a presença de alimentos ricos em FODMAPs que foram excluídos ou reduzidos da dieta habitual, devido a contribuição na exacerbação dos sintomas.

Palavras-chave: Síndrome do colón irritável, carboidratos, Trato Gastrointestinal.

\begin{abstract}
To elucidate the influence of the FODMAP - rich diet on the symptoms of patients with irritable Bowel Syndrome. This is a multiple case study, conducted with patients whith irritable bowel syndrome, conducted in six female subjects. Clinical and dietary evaluation parameters were analyzed, including 24 hour recall and food frequency questionnaire with anthropometric data to result in the participants nutritional status. In addition, the main symptoms and causes of the exacerbation of symptoms were questioned. Data were quantified in graphs and tables of Microsoft Excel 2016, for descriptive analysis. Regarding nutritional status, the patients presente diferente results, with no prevalence. In the food analysis it was possible to acess that most the patients did not have adequate caloric, glycemic, protein and lipid intake, according to the compared parameters. Foods rich in FODMAPs that were excluded or reduced from the usual diet were also observed due to their contribution to the exacerbation of symptoms.
\end{abstract}

Keywords: Irritable colon syndrome, Carbohydrates, Gastrointestinal tract.

${ }^{1}$ Centro Universitário Santo Agostinho (UNIFSA), Teresina - PI. *E-mail: liejylandim@gmail.com 
Resumen: Para dilucidar la influencia de la dieta rica en FODMAP en los síntomas de pacientes con Síndrome de Intestino Irritable, este es un estudio de caso múltiple, realizado con pacientes con Síndrome de Intestino Irritable, en seis mujeres. Se analizaron los parámetros de evaluación clínica y dietética, incluido el cuestionario de recuerdo de 24 horas y frecuencia de alimentos con datos antropométricos para dar como resultado el estado nutricional de los participantes. Además, se cuestionaron los principales síntomas y causa de la exacerbación de los síntomas. Los datos se cuantificaron en gráficos y tablas de Microsoft Excel 2016, para un análisis descriptivo. En cuanto al estado nutricional, los pacientes presentaron resultados diferentes, sin prevalencia. En el análisis de alimentos, fue posible evaluar que la mayoría de los pacientes no tenían una ingesta adecuada de calorías, glucemia, proteínas y lípidos, de acuerdo con los parámetros comparados. También se observó la presencia de alimentos ricos en FODMAP que fueron excluidos o reducidos de la dieta habitual, debido a la contribución en la exacerbación de los síntomas.

Palabras clave: Síndrome de colon irritable, carbohidratos, tracto gastrointestinal.

\section{INTRODUÇÃO}

A síndrome do intestino irritável (SII) é um transtorno complexo e heterogêneo,consiste em uma alteração funcional sem anomalias estruturais e bioquímicas, com sintomas de distensão e dor abdominal, alterações do trânsito intestinal além de múltiplos fatores genéticos, ambientais epsicossociais, alterações na microbiota intestinal, na permeabilidade intestinal, na imune regulação, função motora intestinal, na sensibilidade visceral, bem como a variabilidade nas sensibilidades alimentar onde se ressaltaque osprincipais sintomas se relacionamcom o mau funcionamento intestinal, associados na manifestação de diarreia e constipação (AMARANTE D, 2013; MITCHELL H, et al., 2018; MARUM AP, 2016).

Dados epidemiológicos apontam que a SII afeta $11,2 \%$ de pessoas em todo mundo, porém a falta de publicações de dados em varias regiões equivalentes as bases epidemiologicas de casos de SII, acarreta em dificil montagem no quadro de prevalências mundial desta síndrome, podendo estes dados estarem subestimados. Em estudos epidemiológicos de pesquisas públicas, esta desordem encontra-se mais prevalente no mundo ocidental, que geralmente ocorre em mulheres jovens adultas,entre 20 a 40 anos de idade, apesar desta se desenvolver em qualquer faixa etária (LOPES SS, et al., 2019; LOPES CLR, et al., 2017; WGO, 2015).

Os oligossacarídeos, dissacarídeos, monossacarídeos e polióis fermentáveis (FODMAPs), por serem pequenas moléculas osmoticamente ativas, apresentam má absorção intestinal e rápida fermentação pela microbiota. Dessa forma, a sua ingestão provoca distensão luminal em virtude da maior produção de gases hidrogênio e metano, além de maior fornecimento de água para o cólon; consequentemente há 0 desencadeamento de sintomas gastrointestinais, como diarreia e flatulência (ANDRADE VLA, 2014).

Os FODMAPs têm propriedades funcionais comuns que são mal absorvidos no intestino delgado e isso ocorre por várias causas: há mecanismos de transporte de baixa capacidade através de epitélio (frutose); atividade reduzida de hidrolases de fronteira (lactose); falta de hidrolases (frutanos e glactanos); ou moléculas demasiado grandes para difusão simples (polióis). São moléculas pequenas, portanto, osomoticamente ativa e são rapidamente fermentados por bactérias: a rapidez de fermentação é ditada pelo comprimento da cadeia de hidratos de carbono (quanto menor, mais rapidamente fermentáveis) (BASTOS TFS, 2016).

A Federação Brasileira Gastroenterologia (2017) expõem um quadro de alimentos ricos em FODMAPs que dividem em grupos alimentares, sendo estes frutas, leites e derivados, hortaliças e leguminosas e cereais e massas. São exemplos maçã, leite de vaca,beterraba, pães, entre outros correspondem a estes grupos respectivamente.

Pacientes com SII relatam o início dos sintomas após a ingestão de um ou grupos alimentares específicos, dentre os quaisos mais frequentes são aqueles que apresentam lactose, frutose em excesso de glicose, frutanos, galactooligossacarídeos e polióis, diante disso, terapias alimentares estão sendo ofertadas para o controle da sintomatologia, tendo como uma alternativa adieta com baixo teor em hidratos de carbono 
de cadeia curta fermentáveis. Estima-se que a melhora sintomática possa ser observada entre uma a oito semanas após a introdução da dieta com reduzida quantidade de FODMAPs (ANDRADE VLA, 2014; BASTOS TFS, 2016; SOARES LRS, 2018).

A dieta livre de FODMAPs está bem estabelecida em sua eficácia no manejo dos sintomas da SII, mas a crescente popularidade vem de controvérsias e aplicação inadequada da dieta (HALMOS EP e GIBSON PR, 2019). Com isso, o desenvolvimento de estudos e teorias que busquem contribuir tanto para o progresso de tratamento sem acarretar em complicações, como também para acrescer a qualidade de vida dos indivíduos portadores abrange destaque no benefício do método "low" FODMAP como terapia que contribuirá para um prolongamento nas fases de remissão dos pacientes, sendo coadjuvante na qualidade de vida e na diminuição de terapêuticas farmacológicas. Dessa forma, este estudo tem como objetivo a elucidação da influência da dieta rica em FODMAPs nos sintomas de pacientes com Síndrome do Intestino Irritável.

\section{MÉTODOS}

Tratou-se de um estudo transversal e quantitativo adjunto do método dedutivo. Foi utilizado o estudo de casos múltiplos como ferramenta para a coleta de dados, segundo Eisenhardt KM (1989) para se alcançar uma generalização teórica aceitável. A pesquisa deve possuir um número de casos entre 4 e 10, além disso, declara que um estudo que contenha menos de 4 casos não consegue gerar um bom nível de complexidade, adotando como critério de inclusão indivíduos que possuíam diagnóstico médico de um gastroenterologista e foram excluídos aqueles que fossem menores de 20 anos, ou que continham limitações físicas e portadores de doenças que poderiam interferir no estado nutricional como neoplasias, infecções, alterações neurológicas e gestantes.

O recrutamento dos indivíduos com Síndrome do Intestino Irritável foi realizado por meio de mídias sociais, pelo fato de não conter nenhuma associação ou comunidades que se referem à especialidade deindivíduos com Síndrome do Intestino Irritável. Foi utilizada a seguinte pergunta: "Você possui ou conhece alguém que seja portador da desordem gastrointestinal Síndrome do Intestino Irritável?". A escolha dos participantes foi realizada a partir do interesse e disponibilidade na participação do estudo, além dissoforam selecionados os participantes que se enquadrarem nos critérios de inclusão. Os participantes foram assistidos em uma Clínica Escola de uma Instituição de Ensino Superior em Teresina-Piauí.

Foram coletados dados dietéticos, os quais foramregistrados através de ficha de questionário de frequência alimentar contendo alimentar ricos, intermediários e pobres em FODMAPs, que foram baseados no aplicativo IAPP Guia-FODMAP e foi aplicado um recordatório 24 horas, no qual foi avaliado a ingesta calórica e de macronutrientes (carboidratos, lipídios e proteínas), adjunto de fibras alimentares, através do software Dietbox. Ademais, foram comparados de acordo com os percentuais de macronutrientes estabelecidos pelas Dietary Reference Intakes (DRI's).

Após a avaliação das pacientes e análise da qualidade alimentar foi feita a orientação alimentar, na qual foi explicada todo mecanismo de ação dos FODMAPs no organismo e foi realizada a recomendação de retirada e/ou diminuição de alimentos que seriam causadores da sintomatologia. Além disto, foi entregue uma dieta adaptativa para os mesmos.

Os dados foram quantificados em gráficos e tabelas através do Microsoft Excel 2016 para análise descritiva. O estudo foi submetido à Plataforma Brasil pelo Comitê Nacional de Ética e Pesquisa, que envolve pesquisas com seres humanos. A coleta dos dados só deu início após a emissão do parecer de aprovação CEP/UNIFSA $n^{\circ}$ 3.215.896, e com respectivo $n^{\circ}$ do CAAE 03309518.2.0000.5602 ao concordarem em participar por meio da assinatura do Termo de Consentimento Livre e Esclarecido - TCLE.

\section{RESULTADOS}

Foram atendidos 6 (seis) pacientes com diagnostico de Síndrome do Intestino Irritável pelo um gastroenterologista, sendo todas do sexo feminino. A média de idade foi de 47,3 $\pm 23,9$ anos e a média da altura delas foi equivalente a $154,8 \pm 7,5 \mathrm{~cm}$. De acordo com a Tabela 1, é possível a análise do estado 
nutricional destas pacientes, na qual em relação ao índice de massa corporal (IMC), 16,7\% ( $n=1)$ delas apresentaram desnutrição grau I, 33,3\% ( $n=2)$ eutrofia, 33,3\% $(n=2)$ sobrepeso e 16,7\% $(n=1)$ obesidade.

A ingesta alimentar dos indivíduos assistidos, considerando a composição, (adequação de 90\% a 110\%, segundo recomendação Ministério da Saúde 2004), obtido mediante o percentual de adequação, que é resultado da ingestão atual e a ideal, foi visto que $83.3 \%(n=5)$ das participantes apresentaram os valores calórico, glicídico e proteico superiores ao recomendado. E 50\% ( $n=3)$ possuíram valores lipídicos acima do ideal, este macronutriente em excesso pode estar ligado aos sintomas gastrintestinais.

Foi observado que todas as pacientes disseram diminuir o consumo de alimentos com grande quantidade de fibras, por relacionarem com a piora dos sintomas. Com isso, a ingestão de fibras alimentares de todas as participantes apresentou-se muito abaixo do recomendado para mulheres.

Tabela 1 - Média do consumo energético, macronutrientes e fibras, de acordo com o estado nutricional dos pacientes com Síndrome do Intestino Irritável, Teresina-PI, 2019.

\begin{tabular}{|c|c|c|c|c|c|c|c|c|c|c|}
\hline \multirow{2}{*}{$\begin{array}{c}\text { Estado } \\
\text { Nutricional }\end{array}$} & \multicolumn{2}{|c|}{${ }^{*}$ VET (kcal) } & \multicolumn{2}{|c|}{ Carboidrato (g) } & \multicolumn{2}{|c|}{ Proteína (g) } & \multicolumn{2}{|c|}{ Lipídeo (g) } & \multicolumn{2}{|c|}{ Fibras (g) } \\
\hline & Atual & Ideal & Atual & Ideal & Atual & Ideal & Atual & Ideal & Atual & Ideal \\
\hline $\begin{array}{l}\text { Desnutrido } \\
(n=1)\end{array}$ & 1170,0 & 1697,5 & 132,5 & 233,4 & 78,1 & 85,0 & 34,7 & 47,1 & 15,2 & 25 \\
\hline$\%$ & \multicolumn{2}{|c|}{68,9} & \multicolumn{2}{|c|}{56,8} & \multicolumn{2}{|c|}{91,9} & \multicolumn{2}{|c|}{73,6} & \multicolumn{2}{|c|}{60,9} \\
\hline Eutrófico $(n=2)$ & 1542,0 & 1377,0 & 219,5 & 192,8 & 80,6 & 70,1 & 38,3 & 38,8 & 10,3 & 25,0 \\
\hline$\%$ & \multicolumn{2}{|c|}{111,9} & \multicolumn{2}{|c|}{113,8} & \multicolumn{2}{|c|}{115,0} & \multicolumn{2}{|c|}{98,7} & \multicolumn{2}{|c|}{41,1} \\
\hline $\begin{array}{l}\text { Sobrepeso } \\
(n=2)\end{array}$ & 1944,0 & 1523,0 & 233,3 & 209,7 & 86,1 & 76,2 & 72,7 & 42,3 & 8,4 & 25,0 \\
\hline$\%$ & \multicolumn{2}{|c|}{127,6} & \multicolumn{2}{|c|}{111,2} & \multicolumn{2}{|c|}{113,0} & \multicolumn{2}{|c|}{171,9} & \multicolumn{2}{|c|}{33,6} \\
\hline $\begin{array}{l}\text { Obesidade } \\
\quad(n=1)\end{array}$ & 1657,0 & 1235,0 & 205,7 & 169,8 & 81,3 & 62,0 & 56,8 & 34,3 & 8,1 & 25,0 \\
\hline$\%$ & \multicolumn{2}{|c|}{134,2} & \multicolumn{2}{|c|}{121,2} & \multicolumn{2}{|c|}{131,1} & \multicolumn{2}{|c|}{165,5} & \multicolumn{2}{|c|}{32,3} \\
\hline
\end{tabular}

Legenda: *Valor Energético Total. Fonte: Teles KBF, Sousa SM, Landim LASR, 2019.

O registro de frequência alimentar abordou alimentos ricos, com quantidade intermediária e alimentos pobres em FODMAPs, sendo explorados mais profundamente os alimentos cuja quantidade de FODMAPs eram maiores. Além disso, fossem mais comuns no hodierno das participantes (Tabela 2).

Foi visto que o leite e seus derivados, algumas frutas, como a ameixa, e produtos com base de trigo foram os mais relatados por serem excluídos da alimentação diária das pacientes. Quando questionado no âmbito de alimentos em geral, o trigo, feijão e leites e seus derivados foram classificados como alimentos exacerbadores de sinais e sintomas da patologia, sendo estes compostos por carboidratos fermentadores, como frutanos, lactose, polióis, oligossacarídios, galactanos. Em contrapartida, algumas das participantes afirmaram sentirem desconforto e alterações gastrointestinais após o consumo de destes alimentos, no entanto não excluíram da rotina alimentar.

Dentre sinais e sintomas mais mencionados pelas pacientes estão diarreia, dores abdominais, enjoos, vômitos, constipação e sensação de esvaziamento após evacuação. Metade das pacientes ( $n=3-50 \%)$ relataram a exacerbação dos sintomas após episódios emocionais como situações envolvendo ansiedade, nervosismo, preocupação ou eventos que levem a complicações psicossociais, podendo ter relação com a sintomatologia frequente dita pelas participantes. 
Tabela 2 - Frequência alimentar de alimentos ricos em FODMAPs por pacientes com Síndrome do Intestino Irritável, Teresina-PI, 2019.

\begin{tabular}{|c|c|c|c|c|c|c|}
\hline \multirow{3}{*}{ Alimentos } & \multicolumn{6}{|c|}{ Frequência alimentar } \\
\hline & 2 a 3x/dia & $1 \times /$ dia & 5 a $6 x /$ sem & 2 a $4 x /$ sem & 1 a $3 x /$ mês & $\begin{array}{c}\text { Nunca/quase } \\
\text { nunca }\end{array}$ \\
\hline & $\mathrm{N}$ & $\mathrm{n}$ & $\mathrm{n}$ & $\mathrm{N}$ & $\mathrm{n}$ & $\mathrm{n}$ \\
\hline Suco de frutas & 1 & 1 & & & & 4 \\
\hline Abacate & & & & 2 & 3 & 1 \\
\hline Ameixa & & & & & 2 & 4 \\
\hline Banana madura & 1 & & 1 & 4 & & \\
\hline Maçã & 1 & & & & 3 & 2 \\
\hline Cebola & 1 & 3 & & 2 & & \\
\hline Ervilha & 1 & & & 1 & 1 & 3 \\
\hline Feijão & 1 & 1 & & 2 & 1 & 1 \\
\hline logurte & 2 & & & 1 & 1 & 2 \\
\hline Leite condensado & & & & & 2 & 4 \\
\hline Leite de vaca & & 1 & & 1 & & 4 \\
\hline Requeijão/light & & & & 1 & 1 & 4 \\
\hline Sorvete & & & & & 4 & 2 \\
\hline Biscoito de farinha de trigo & & & & & 2 & 4 \\
\hline Cuscuz & & 3 & & 2 & & 1 \\
\hline Macarrão com farinha de trigo & & & & 2 & 3 & 1 \\
\hline Pão de trigo branco/integral & 1 & 1 & 2 & 1 & & 1 \\
\hline
\end{tabular}

Fonte: Teles KBF, Sousa SM, Landim LASR, 2019.

\section{DISCUSSÃO}

A prevalência do sexo feminino com a síndrome do intestino irritável é notório na pesquisa onde a prevalência estimada da SII na população geral foi de 10 a 20\%, acometendo predominantemente mulheres entre 20 e 40 anos, tendo a iniciar na adolescência por volta dos 20 anos, causando principais sintomas, porém aparecem e desaparecem em intervalos irregulares (PASSOS MCF, 2012; MOLESKI SM, 2019). As mulheres são diagnosticadas duas a três vezes mais do que os homens. De acordo com Makharia GK (2011), isso se deve aos hormônios sexuais femininos que afetam a motilidade gastrintestinal e diferenças na síntese de serotonina no cérebro são mecanismos propostos para maior ocorrência de distúrbios da motilidade em mulheres.

A fisiopatologia desta doença ainda não é conclusiva. Sabe-se que a ativação imunológica e a inflamação da mucosa intestinal estão associadas à causa da doença. A hipersensibilidade visceral é uma resposta aumentada dos circuitos neuroimunes no sistema nervoso ou no trato gastrintestinal, no qual existem estímulos de irritações, inflamações e infecção que prejudica o funcionamento adequado predispondo a SII. Frequente lesão gastrointestinal pode resultar em anormalidades na funcionalidade, induzindo os sintomas da síndrome do intestino irritável (PEREIRA M, et al., 2013).

Houte KVD, et al. (2019) observou em seu estudo que inchaço, diarréia, flatulência, dores abdominais e constipação foram os sintomas mais relatados com frequência pela população estudada, a amostra refrente a atual pesquisa referiu que a diarreia, dores abdominais, enjoos, vômitos, constipação e sensação de esvaziamento após evacuação foram os sintomas mais frequentes.

A influência dos fatores psicológicos é notável nos doentes, podendo influir nos sintomas e na evolução clínica destes. Estudos demonstram que alterações de humor e outros transtornos mentais são mais comuns em pacientes portadores da SIl quando comparados com os sujeitos sadios, pois a alteração do eixo intestinocérebro, devido também à diminuição na produção de serotonina, corrobora na diminuição do limiar para as sensações de dor e incômodo gastrintestinal (CRUZ CKNV, 2016; PEDREIRA M, et al., 2013). 
Segundo Vedovato K, et al. (2014), a serotonina é considerada um dos neurotransmissores-chave para o trato gastrointestinal, afetando a sensação de motilidade e secreção intestinal, ademais atua na ativação e condução da informação ao sistema nervoso central (SNC).

A princípio, é importante salientar que o consumo adequado tanto de macronutrientes quanto de calorias, é necessário para manter as funções do organismo. A existência de fatores que causem um desequilíbrio entre esses componentes pode levar ao desenvolvimento de algum problema de saúde. Segundo Lopes SS, et al. (2019) o aumento do teor de fibra alimentar em uma dieta pode melhorar a consistência fecal e influenciar diretamente na maior frequência de evacuação de fezes para indivíduos com SIl estas são fermentadas no cólon com produção de ácidos graxos de cadeia curta (AGCC) e gás. Provavelmente pela geração de AGCC, atrai água e flora microbiota, aumentando o bolo fecal. O resultado é uma aceleração do tempo de trânsito no cólon.

Segundo McRorie JW e McKeown NM (2017), as fibras fermentáveis solúveis não exercem efeito laxante, como por exemplo, frutooligossacarídeo e dextrina de trigo, e certas fibras podem ser constipantes, como a dextrina de trigo e insolúvel fino. Em especial, as fibras solúveis em doentes com sintomas ligeiros podem diminuir os sintomas. Todavia, dependendo do tipo de síndrome que se enquadra o paciente a ingestão de fibras pode contribuir para a produção de gases abdominais com consequentes dores e distensão abdominal (LOPES SS, et al., 2019; ARAÚJO JPC, 2016).

Amarante D (2013) encontrou em seu estudo que feijão, café e pizza seriam alimentos mais agressores nos sintomas dos pacientes com Síndrome do Intestino Irritável $(n=140)$, com percentuais de 41,4\%, 40,7\% e $36,6 \%$ respectivamente. Dados estes que são semelhantes quando comparados ao presente estudo, no qual o trigo, feijão e leites e seus derivados foram diminuídos da ingesta da maioria das pacientes.

Isso porque, segundo Shepherd SJ, et al. (2013), o trigo e feijões são principais exemplos de a-galactooligossacáridos eoligossacarídeos frutanos, respectivamente,e que todos os humanos não possuem enzimas que hidrolisem esses oligossacarídeos; portanto, não são digeridos ou absorvidos e, com a chegada destes no cólon, são prontamente fermentados pela microbiota do cólon, e, em alguns casos, produzindo gás. Por conseguinte, haverá maior consequência nos sintomas em pacientes com Síndrome do Intestino Irritável. Ferreira F e Inácio $F(2018)$ completam que o trigo é rico em glutén e apesar deste não ser classificado como FODMAP, gêneros alimentícios com ausência de glutén em sua composição podem contribuir para indivíduos com sensibilidade a estes carboidratos, motivo destes produtos também conterem quantidades baixas de frutanos e oligossacarídeos. Soares RLS (2018) aponta outra possível explicação para o trigo ter relação com inflamações intestinais, é o fato de serem utilizados inibidores para eliminar pragas resistentes em cereais, como o trigo, sendo que estes tem elevado potencial inflamatótio para pacientes com SII. A Federação Brasileira de Gastenterologia (2017) afirma que o café preto não contém carboidratos fermentadores, todavia, a cafeína presente neste pode estimular os movimentos intestinais e consequentemente isso pode ser um desconforto para algumas pessoas.

A exclusão e o baixo consumo de pão de trigo e biscoito de farinha de trigo pela maioria das pacientes também podem ser explicados devido à alta presença de fibras e frutanos e conseqüente piora nos sintomas de correntes da Síndrome do Intestino Irritável. A frutose e outros Fodmaps que não são absorvidos podem estar envolvidos na gênese de sintomas gastrintestinais observados nos distúrbios gastrintestinais funcionais. Ozaki RKF, et al. (2018) concluíram em seu estudo que a má absorção intestinal de frutose associou-se com maior capacidade de fermentação no intestino, sendo que a má absorção desse monossacarídeos relacionou com os maiores valores de IMC para a idade da amostra estudada.

A lactose não absorvida passa para o cólon, sofrendo fermentação bacteriana, com produção de gases e AGCC, resultando em sintomas de intolerância à lactose (IL), ou seja, flatulência, diarreia, distensão e dor abdominal. Quando correlacionada com a SII, não apresenta relevância definida com a sintomatologia desta patologia, visto que em alguns estudos randomizados não observaram melhora significativa dos sintomas intestinais com a restrição da lactose ou uso de lactase. Acredita-se que, apesar da lactose ser considerada um FODMAP, mesmo nos pacientes com deficiência a enzima que degrada a lactose, a restrição desse dissacarídeo raramente trará completa melhora dos sintomas (CRUZ CKNV, 2016). 


\section{CONCLUSÃO}

O recente aumento de pesquisas científicas sobre distúrbios da SIl e FODMAPs é visível e justificado, através deles é apontado que alimentos ricos em carboidratos fermentadores, como frutanos, lactose, polióis, oligossacarídios, galactanos podem ter relação direta com a piora no quadro sintomático de portadores da Síndrome do Intestino Irritável. A partir da análise alimentar foi possível avaliar que a maioria das pacientes não estava com a ingesta calórica, glicídica, protéica e lipídica adequada, de acordo com os parâmetros comparados. Observou-se também a presença de alimentos ricos em FODMAPs que foram excluídos ou reduzidos da dieta habitual, devido a contribuição na exacerbação dos sintomas. Com isso, além desse estudo contribuir para o aprofundamento do conhecimento acerca deste tema, servindo de subsídio para futuras pesquisas.

\section{REFERÊNCIAS}

1. AMARANTE D. Aspectos nutricionais na população de pacientes com Síndrome do Intestino Irritável atendidos nos Hospital das Clínicas da Faculdade de Medicina da Universidade de São Paulo. Dissertação (mestrado). Faculdade de Medicina da Faculdade de São Paulo. São Paulo, 2013.

2. ANDRADE VLA, et al. Dieta restrita de FODMEPs como opção terapêutica na síndrome do intestino irritável: revisão sistemática. GED gastroenterol. Endosc, 2014; 34(1): 34-41.

3. BASTO TFS. Síndrome do intestino irritável e dietas com restrição de FODMAPs. Dissertação (Mestrado Integrado em medicina) -Faculdade de medicina da universidade de Lisboa, 2015/2016.

4. COSTA JBF, et al. A dieta low-fodmap e suas indicações clínicas nas doenças do trato gastrointestinal. III Canbracis, 2018.

5. CRUZ CKNV. Síndrome do intestino irritável: aspectos clínicos, psicológicos e nutricionais. Associação entre trânsito orocecal prolongado e supercrescimento bacteriano. Dissertação (Mestrado em medicina) - Faculdade e de Ciências Médicas da Universidade Estadual de Campinas, Campinas, 2016.

6. EISENHARDT KM. Building Theories from Case Study Research. The Academy of Management Review. 1989.

7. FERREIRA F e INÁCIO F. Patogia associada ao trigo: Alergia lgE e não IgE mediada, doença celíaca, hipersensibilidade não celíaca. Revista portuguesa de imunoalergologia, 2018; 3: 171-187.

8. HALMOS EP e GILBSON PR. Controversies and reality of the FODMAP diet for patients with irritable bowel syndrome. Journal Gastroenterolo gyand Hepatology, 2019.

9. HOUTE KVD, et al. Prevalência e impacto dos sintomas auto-relatados do intestino irritável na população em geral. United Europeia Gastroenteral J. 2019; 7(2): 307-315.

10. LOPES CLR, et al. Prevalência de sinais e sintomas de disbiose intestinal em pacientes de uma clínica em TeresinaPI, 2017; 10(3): 280-292.

11. LOPES SS, et al. Avaliação do consumo alimentar de pacientes com síndrome do intestino irritável em acompanhamento ambulatorial. Arq. Gastroenterol, 2019; 56(1): 3-9.

12. MAKHARIA GK, et al. Prevalence of irritable bowel syndrome: a community based study from northern India. Pubmed, $2011 ; 1(17): 70-87$.

13. MCRORIE JW e MCKEOWN NM. Understanding the Physics of Functional Fibers in the Gastrointestinal Tract: An Evidence-Based Approach to Resolving Enduring Misconceptions about Insoluble and Soluble Fiber, 2016; 117(2): 251-264.

14. MITCHELL $\mathrm{H}$, et al. Review article: Implementation of a diet low in FODMAPs for pacientes with irritable bowel syndrome- directions for future research. Aliment Pharmacology \& tlerapeutics. 2018.

15. MOLESKI SM. Síndrome do intestino irritável (SII): Cólon espástico. In: MANUAL MDS, 2019. Disponível em: https://www.msdmanuals.com/pt-br/casa/dist\%C3\%BArbios-digestivos/s\%C3\%ADndrome-do-intestinoirrit\%C3\%A1vel-sii/s\%C3\%ADndrome-do-intestino-irrit\%C3\%A1vel-sii. Acesso em: 8 out. 2019.

16. MURUM AP. Uma intervenção Nutricional com restrição de FODMAPs integrada no tratamento da fibromialgia uma realidade com benefícios? Dissertação (Mestrado em Nutrição Clínica) - Instituto Politécnica de Lisboa. Universidade de Liaboa, 2016.

17. OZAKI RKF, et al. Intestinal fructose malabsorption is associated with increased lactulose fermentation in the intestinal lumen. Jornal pediatra. 2018; 94(6): 609-615.

18. PASSOS MCF. Síndrome do trato intestinal irritável- Diagnóstico e tratamento. GED gastroenterol. Endosc, 2012.

19. PEDREIRA M, et al. Prevalência de síndrome do intestino irritável em estudantes de medicina. Revista Brasileira de Neurologia e Psiquiatria, 2013; 7(2): 51-53. 
20. SHEPHERD SJ, et al. Short-Chain carbohydrates and functional gastrointestinal disorders. The american jornal of gastroenterology, 2013.

21. SOARES RLS. Irritable bowel syndrome, food intolerance and non-celiac glúten sensitivity. A new clinicalchallenge.Arq. Gastroentol. 2018.

22. VEDOVATO K, et al. O eixo intestino-cérebro e o papel da serotonina. Arq. Ciênc. Saúde Unipar, Umuarama, 2014; 18 (1): 33-42, jan./abr.

23. WHELAN K, et al. The low FODMAP diet in the management of irritable bowel syndrome: na evidence-based review of FODMAP restriction, reintroduction and personalisation in clinical practice. Journal of human nutrition and dietetics. 2018. 